\title{
Frequency and mortality of septic shock in Europe and North America: a systematic review and meta-analysis
}

\author{
Jean-Louis Vincent ${ }^{1 *}$ (D), Gabriel Jones ${ }^{2}$, Sholto David ${ }^{2}$, Elena Olariu² and Kevin K. Cadwell ${ }^{2}$
}

\begin{abstract}
Background: Septic shock is the most severe form of sepsis, in which profound underlying abnormalities in circulatory and cellular/metabolic parameters lead to substantially increased mortality. A clear understanding and up-to-date assessment of the burden and epidemiology of septic shock are needed to help guide resource allocation and thus ultimately improve patient care. The aim of this systematic review and meta-analysis was therefore to provide a recent evaluation of the frequency of septic shock in intensive care units (ICUs) and associated ICU and hospital mortality.

Methods: We searched MEDLINE, Embase, and the Cochrane Library from 1 January 2005 to 20 February 2018 for observational studies that reported on the frequency and mortality of septic shock. Four reviewers independently selected studies and extracted data. Disagreements were resolved via consensus. Random effects meta-analyses were performed to estimate pooled frequency of septic shock diagnosed at admission and during the ICU stay and to estimate septic shock mortality in the ICU, hospital, and at 28 or 30 days.

Results: The literature search identified 6291 records of which 71 articles met the inclusion criteria. The frequency of septic shock was estimated at $10.4 \%$ (95\% Cl 5.9 to 16.1\%) in studies reporting values for patients diagnosed at ICU admission and at $8.3 \%(95 \% \mathrm{Cl} 6.1$ to $10.7 \%)$ in studies reporting values for patients diagnosed at any time during the ICU stay. ICU mortality was $37.3 \%$ (95\% Cl 31.5 to $43.5 \%$ ), hospital mortality $39.0 \%$ (95\% Cl 34.4 to 43. 9\%), and 28-/30-day mortality $36.7 \%$ (95\% Cl 32.8 to 40.8\%). Significant between-study heterogeneity was observed.

Conclusions: Our literature review reaffirms the continued common occurrence of septic shock and estimates a high mortality of around 38\%. The high level of heterogeneity observed in this review may be driven by variability in defining and applying the diagnostic criteria, as well as differences in treatment and care across settings and countries.
\end{abstract}

Keywords: Sepsis, Intensive care, Heterogeneity, Outcome, Sepsis definition

\section{Introduction}

Sepsis, the association of organ dysfunction with an infection, is a complex multifactorial disease that has severe health and economic burden on both the patient and healthcare systems worldwide. Sepsis is one of the leading causes of death and critical illness in the world [1, 2], with in-hospital mortality rates in the USA as high as $25-30 \%$ [3]. Data drawn principally from large retrospective database studies point to high population-level incidence rates for sepsis among patients hospitalized in high-income

\footnotetext{
* Correspondence: jlvincent@intensive.org

${ }^{1}$ Department of Intensive Care, Erasme Hospital, Université libre de Bruxelles,

Route de Lennik 808, 1070 Brussels, Belgium

Full list of author information is available at the end of the article
}

countries; indeed, admissions of patients with sepsis exceed those of patients who have suffered myocardial infarction or stroke $[4,5]$. The incidence of sepsis in developed countries has been reported to be increasing [6,7], although this is controversial and may in large part be a phenomenon of reporting bias related to financial reimbursement, increased awareness of sepsis definitions among medical professionals, and changes in diagnostic codes [8-11]. A recent study in which sepsis was defined according to the latest guidelines suggested relative stability in the rate of sepsis from 2002 to 2012 [12].

Septic shock, characterized by arterial hypotension, altered tissue perfusion, and increased blood lactate levels $[13,14]$, is the most severe form of sepsis. In 2016, 
Shankar-Hari et al. [15] conducted a systematic review to evaluate clinical criteria currently used to identify septic shock. They reported worldwide estimates for hospital mortality but provided no information on intensive care unit (ICU) or 28-/30-day mortality rates or on the frequency of septic shock. Moreover, Shankar-Hari et al. included data from patients enrolled between 1989 and 2015 (publications from 1992 to 2015), yet our awareness of sepsis has increased considerably since then and patient management has also changed.

We therefore conducted an updated systematic review to identify observational studies conducted in Europe and North America that reported epidemiological data of patients with septic shock. This was followed by a quantitative meta-analysis to determine the frequency of septic shock and its associated mortality.

\section{Materials and methods}

A systematic review protocol was prepared based on the Preferred Reporting Items for Systematic Review and Meta-Analysis Protocols (PRISMA-P) [16] and in accordance with established guidelines from The Cochrane Handbook for Systematic Reviews of Interventions [17] and the Center for Reviews and Dissemination [18].

\section{Search strategy}

A comprehensive literature search strategy combining Medical Subject Headings (MeSH) and free text terms for the epidemiology of septic shock, health-related quality of life, costs, and treatment guidelines was used to retrieve articles of interest from MEDLINE, MEDLINE In-Process Citations \& Daily Update, Embase, and the Cochrane Library databases. Searches were limited to papers published between 1 January 2005 and 20 February 2018. Full search strategies are provided in Additional file 1.

\section{Study selection criteria}

Observational studies of adult patients (aged $\geq 15$ years) with sepsis were eligible for inclusion if they reported data on either frequency or mortality of septic shock. Studies were limited to those conducted in Europe, the USA, or Canada. For the frequency assessment, they must have included cohorts of $\geq 100$ patients, and for the mortality assessment, cohorts of $\geq 15$ patients. Non-observational studies or studies of patients within specific disease groups or other exclusive populations were excluded. Conference abstracts, reviews, systematic reviews, and studies indexed as case reports, editorials, and letters were also excluded. The full list of inclusion and exclusion criteria is available in Additional file 1.

\section{Screening and study selection}

Double screening was performed, with four authors (K.K.C., E.O., S.D., and G.J.) in pairs providing an independent assessment of the titles and abstracts of all records retrieved in the electronic searches. The full text of each study that met the criteria for inclusion was then reviewed, with discrepancies between the reviewers resolved through discussion.

\section{Data extraction}

The following data were extracted from papers identified at full-text screening: article identifiers (authors, year of publication, objective), study identifiers (sample size, design, country, length of follow-up, inclusion criteria, definition and criteria used for identifying septic shock, comorbidities, number of organ failures), setting and population (age, sex, reason for admission, severity scores, acquisition of infection, microorganisms identified), and outcome measures (frequency, incidence, mortality).

\section{Assessment of methodological quality}

Quality assessments of the studies that were eligible for meta-analysis were performed using "The Joanna Briggs Institute Critical Appraisal Checklist for studies reporting prevalence data" [19] for frequency studies, with a modified version of "The Joanna Briggs Institute Critical Appraisal Checklist for case series" [20] used for studies reporting mortality.

\section{Statistical analysis and meta-analyses}

Random effects meta-analyses were performed to estimate pooled frequencies of septic shock diagnosed at admission or during the ICU stay and to estimate septic shock mortality in the ICU, hospital, and at 28 or 30 days. Separate analyses were performed on studies in which The Third International Consensus Definitions for Sepsis and Septic Shock (Sepsis-3) [14] were used, as this introduced hyperlactatemia as a component for septic shock. Using frequency and mortality rates from patients diagnosed with Sepsis-3 definitions was considered a potential source of heterogeneity given the more narrowly defined, more severe patients these criteria would identify with the addition of this component. Unless otherwise stated, estimates given are derived from studies in which any criteria except Sepsis-3 are used to identify septic shock. Confidence intervals for individual studies were calculated using the Clopper-Pearson method and between-study variances were estimated using the DerSimonian-Laird technique. For frequency, data were pooled using the inverse-variance method and the Freeman-Tukey double arcsine transformation to calculate an overall proportion, before back transformation to the original scale and the logit transformation were used to pool hospital mortality data. A continuity correction of 0.5 was applied in studies with zero cell frequencies. Statistical heterogeneity was assessed 
visually using forest plots and formally using the $I^{2}$ statistic; heterogeneity was considered to be high for $I^{2}$ values greater than $75 \%$ [21].

For frequency, two meta-analyses were performed according to the time of septic shock diagnosis reported in the study (at ICU admission or at any time during the ICU stay). For mortality, three meta-analyses were performed according to the type of reported mortality: ICU mortality, in-hospital mortality, and mortality at either 28 or 30 days. Subgroup meta-analyses for frequency and mortality were performed for European vs North American studies, and for single center vs multicenter studies. Publications that did not report data as proportions $(n / N)$ but as percentages were excluded if the proportions could not be accurately back-calculated. Studies that reported 1-day point prevalence estimates were also excluded from the meta-analyses.

All analyses were performed using $\mathrm{R}$ software (www. R-project.org) and the package "meta" (general package for meta-analysis) (https://cran.r-project.org/web/packages/meta/meta.pdf).

\section{Results}

\section{Study selection}

The literature search identified 6291 records following de-duplication. Following title and abstract screening 460 articles met the criteria for full-text evaluation. A total of 71 met the eligibility criteria and were included in the qualitative systematic review; 50 publications reported data from Europe and 21 publications reported data from North America. Full details of study selection and exclusions are shown in the PRISMA flow diagram in Additional file 1: Figure S1.

Frequency data were reported in 36 of the 71 publications covering 27 individual studies/datasets [22-57] (Additional file 1: Table S1). Data from the Sepsis Occurrence in Acutely Ill Patients (SOAP) study were reported in four separate publications [26-28, 32]; data from a single 1-day frequency study from Germany were reported in two publications [29, 34]; the French EPIdemiology of Septic Shock study (EPISS) was detailed in two publications [46, 47]; a multicenter study from the Piedmont Intensive Care Unit Network in Italy was reported in two publications [48, 49]; the OUTCOMEREA database was used for three publications [22, 36, 51]; and the Portuguese Community-Acquired Sepsis (SACiUCI) study was reported in two publications [37, 39]. Mortality data were reported in 62 publications covering 57 individual studies $[10,23-28,31,32,34,35,37-43,45-48,50-52,54,55$, 57-91] (Additional file 1: Table S2).

\section{Quality assessment}

The proportion of studies that fulfilled each item on the quality assurance checklist is shown in Additional file 1:
Tables S3 and S4 for the studies that report frequency data and mortality data, respectively. For frequency, the areas that raised concern were the validity of methods used for identification of septic shock, the reliability of septic shock diagnosis among patients, and rate of response and methods employed to manage low response rate. For mortality, the areas that raised concern were, again, the reliability of septic shock diagnosis among patients, in addition to completeness of inclusion, and clear reporting of demographics of the septic shock patients.

\section{Frequency estimates}

Frequency estimates ranged from 2.5\% [25] to $23.4 \%$ [57] when septic shock was diagnosed at ICU admission (Additional file 1: Table S1). Three studies reported 1 -day point prevalence estimates for frequency and were excluded from the meta-analyses [29, 34, 53]. The overall pooled frequency of septic shock was estimated at $10.4 \%$ (95\% CI 5.9 to $16.1 \%$ ) with a high level of heterogeneity $\left(I^{2}=100 \% ; p=0\right)$ (Fig. 1$)$. This pooled frequency decreased to $6.5 \%$ (95\% CI 5.6 to $7.5 \%$ ) when using Sepsis-3 criteria. When septic shock was diagnosed at any time during the ICU stay, estimates ranged from $1.4 \%$ [41] to 27.6\% [38] (Additional file 1: Table S1) and the overall pooled frequency of septic shock was estimated at $8.3 \%$ (95\% CI 6.1 to 10.7\%) with a high level of heterogeneity $\left(I^{2}=99 \% ; p=0\right)$ (Fig. 2). Estimates for septic shock frequency at admission and at any time during the ICU stay were higher in European populations than in North American populations $(11.4 \%$ vs. $6.0 \%$ and $8.9 \%$ vs. $4.6 \%$ respectively; see Additional file 1: Figures S2 and S3). Estimates for septic shock frequency at admission were higher in multicenter than in single-center studies $(10.6 \%$ vs. $9.0 \%)$, but the reverse was true for septic shock frequency during the ICU stay $(7.6 \%$ vs. 9.9\%); none of these differences were statistically significant (Additional file 1: Figures S4 and S5).

\section{Mortality}

Mortality rates in the included studies are reported in Additional file 1: Table S2. Three random-effects metaanalyses were performed to evaluate the mortality of septic shock in the ICU, in the hospital and at 28/30 days; these are shown in Figs. 3, 4, and 5. For seven of the publications reporting mortality, the number of patients could not be calculated and these were excluded from the meta-analyses [37, 39, 58, 67, 79, 88, 90]. One study reported a 1-day point prevalence estimate for hospital mortality and was excluded from the meta-analysis [34]. The mean mortality was $37.3 \%$ (95\% CI $31.5 \%$ to $43.5 \%$ ) in the ICU and $39.0 \%$ (95\% CI $34.4 \%$ to $43.9 \%$ ) in-hospital. Mortality at 28/30 days was estimated at $36.7 \%$ (95\% CI $32.8 \%$ to $40.8 \%$ ). Statistically significant heterogeneity was observed in all meta-analyses with 


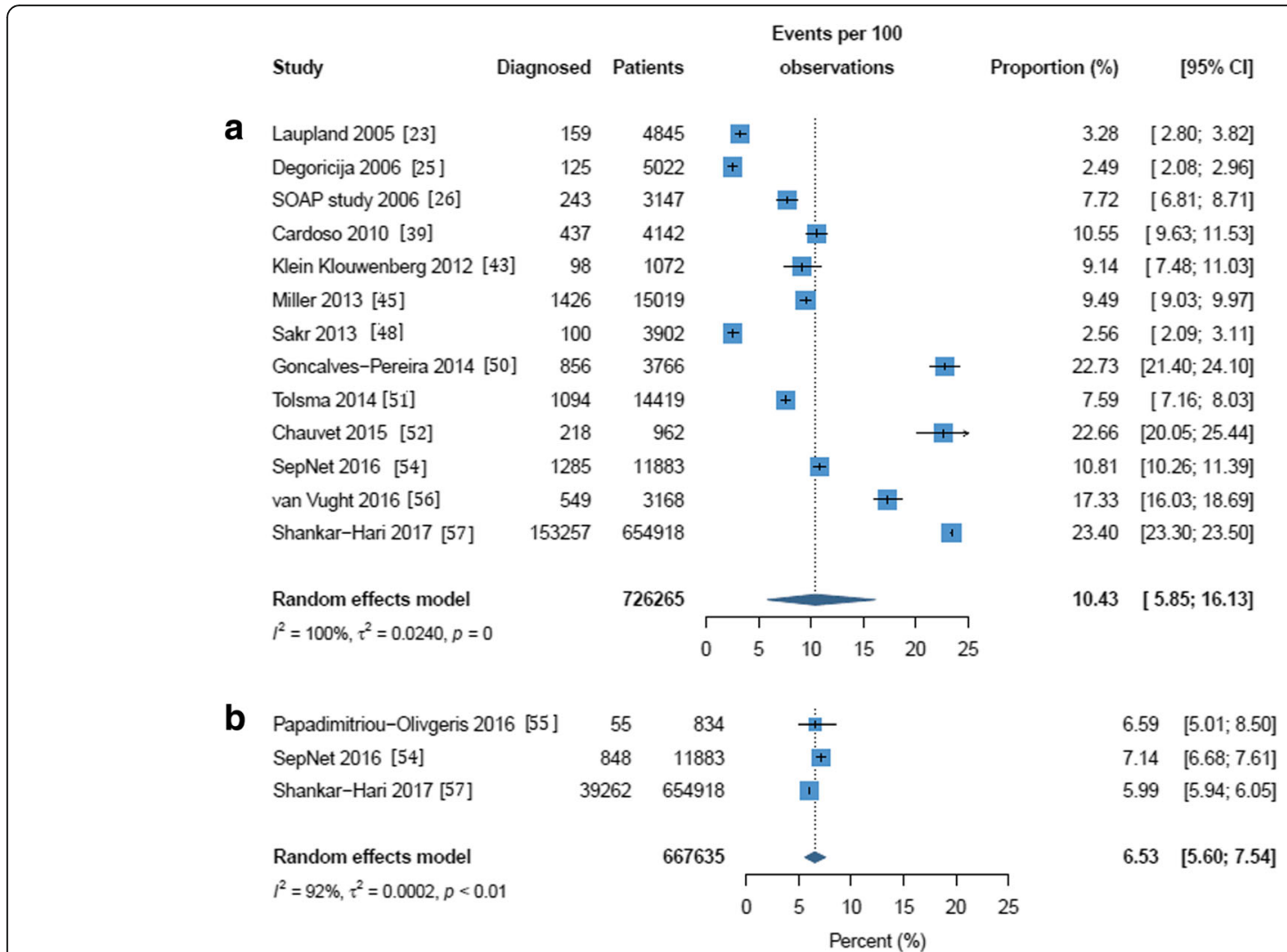

Fig. 1 Frequency of septic shock in a cohort of patients admitted to the intensive care unit and diagnosed on admission. (a) All definitions except Sepsis-3. (b) Sepsis-3 only. The forest plots contain exact 95\% confidence intervals, and specific studies are weighted using the inversevariance method. The pooled summaries are obtained using the Freeman-Tukey double arcsine transformation and the DerSimonian-Laird method estimates between-study variance

reported $I^{2}$ values of 98, 100, and 90 for in-ICU, in-hospital, and 28-/30-day mortality, respectively. ICU and hospital mortality estimates increased to $51.9 \%(95 \%$ CI 43.9 to $59.8 \%)$ and $52.1 \%$ (95\% CI 51.6 to $52.6 \%)$ respectively when septic shock was diagnosed using Sepsis-3 criteria. As with frequency, estimates for mortality in the ICU and hospital and at 28/30 days were all higher in European populations than in North American populations ( $37.9 \%$ vs. $32.8 \%, 42.7 \%$ vs. $32.3 \%$, and $38.5 \%$ vs. $33.2 \%$ ) though not significantly so (see Additional file 1: Figures S6-S8). Estimates for ICU, hospital, and 28-/30-day mortality were higher in multicenter than in single-center studies $(41.8 \%$ vs $37.1 \%, 43.1 \%$ vs. $34.0 \%$, and $37.2 \%$ vs. $36.2 \%$, respectively; Additional file 1: Figures S9-S11); none of these differences were statistically significant.

\section{Discussion}

Our systematic review shows that approximately $10 \%$ of ICU patients have septic shock at admission and $8 \%$ of patients admitted to the ICU have septic shock sometime during their ICU stay. Populations assessed using Sepsis-3 criteria had a lower estimate at admission (approximately 7\%). This may be a result of the narrower definition used in comparison to previous consensus criteria [92]. Earlier versions of the sepsis consensus definitions did not take into account lactate levels and required that patients met 2 or more systemic inflammatory response syndrome (SIRS) criteria; therefore, they are likely to be more inclusive $[38,93,94]$. The high occurrence of septic shock among ICU patients supports current efforts to raise awareness of the condition among healthcare professionals and the general public, but caution should be exercised when interpreting our pooled estimates given the high heterogeneity observed between studies. This variability in estimates could be driven by patient populations and, as the European- and North American-specific estimates suggest, country of origin. The different methods of identifying cases, using discharge codes, administrative data, or electronic chart reviews, might also account for some of the differences. For example, some coding abstraction methods may underestimate the diagnosis [95] and significant numbers of patients may be misclassified by electronic health record-based definitions when the frequency of the condition is low [96]. Additionally, the higher number of septic shock cases reported in some countries 


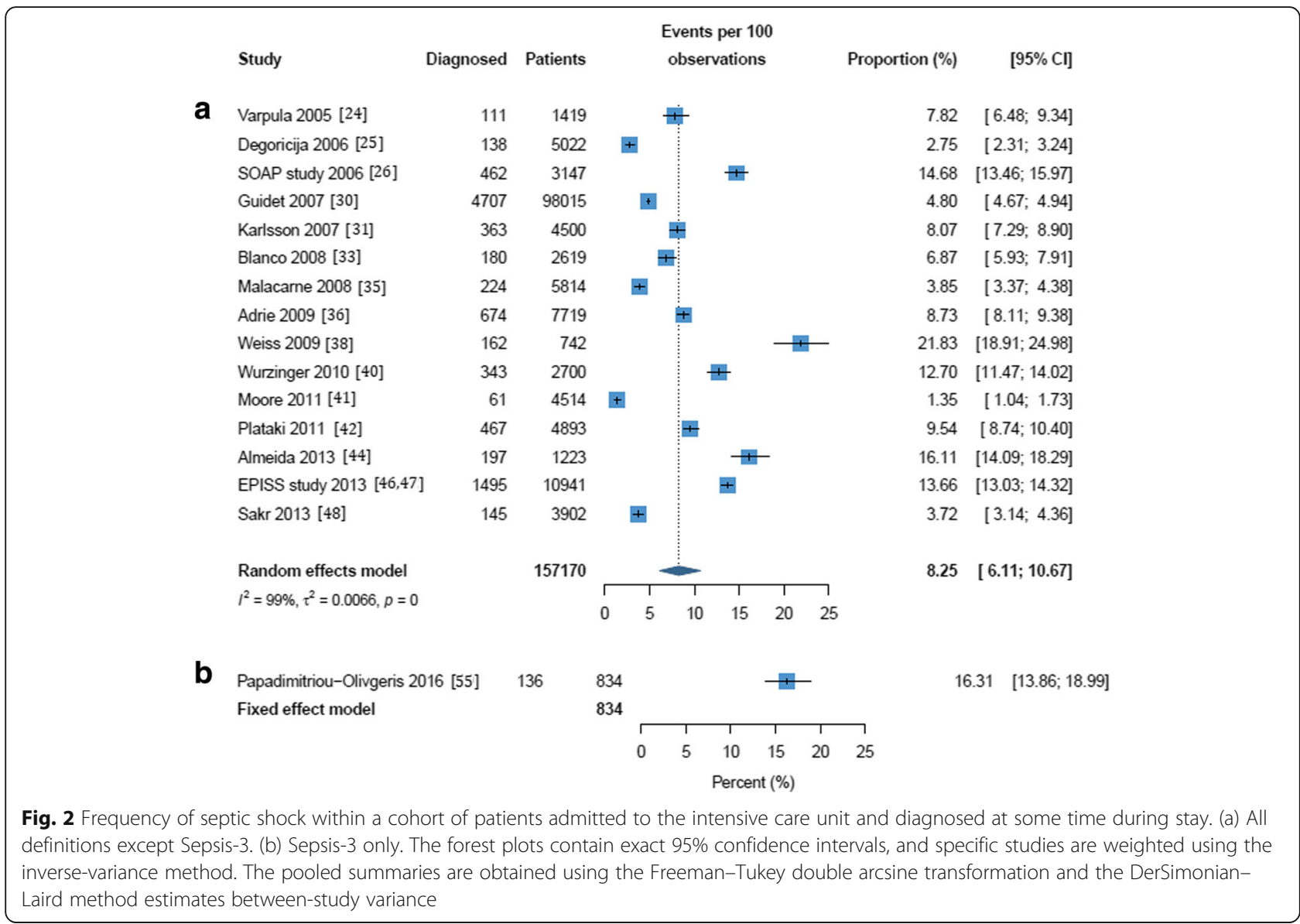

may partly be explained by the lower number of ICU beds resulting in a concentration of more severely ill patients. For example, a study of Portuguese ICUs revealed an unusually high frequency of septic shock diagnosed at admission (approximately 23\%) that the authors suggested was most probably related to the lack of ICU services in Portugal [50]. The differences observed might also be due to seasonal variations in the epidemiology of septic shock as the time period of the studies varied widely from a single day to several years. Additionally, the reporting of the data was not always satisfactory. Many studies collected data from a mix of patients diagnosed either at admission or screened prospectively during their ICU stay. These data were often not reported separately, so our estimates may be a mix of frequency and incidence rates.

Our results show that, regardless of the time-point of assessment, the septic shock mortality rate is approximately $38 \%$. This is somewhat lower than the results of the systematic review conducted by Shankar-Hari et al. that estimated a septic shock-associated crude mortality of $46.5 \%$ [15]. This may be a result of the inclusion of some long-term follow-up data by Shankar-Hari et al. whereas the current review focused on short-term mortality. Moreover, the Shankar-Hari review included studies in which patient data were collected prior to 1995 when mortality rates may have been higher on average than in more recent studies. Indeed, 20-25 years ago, non-selected populations had a crude mortality rate for septic shock of more than $50 \%$ [97, 98]. In the years since, observational studies have reported higher survival rates [7, 46, 99-102], likely because of improvements in the general management of patients with septic shock. Our estimates for 28-30-day mortality are higher than those identified by a systematic review on long-term mortality [103], which reported post-acute phase mortality (difference in proportion between cumulative 1-year mortality and acute mortality) of $16.1 \%$ (95\% CI 14.1 to $18.1 \%$ ), levels that are likely to incur a high burden on overall costs and quality of life. Estimates for ICU and in-hospital mortality were higher using Sepsis-3 criteria than non-Sepsis- 3 criteria ( $52 \%$ vs. $37 \%$ and $52 \%$ vs. $39 \%$ ), which may be a result of the greater severity of disease associated with the addition of hyperlactatemia as a component for septic shock diagnosis. This is consistent with previous research that found that Sepsis-3 identified patients who were more advanced 


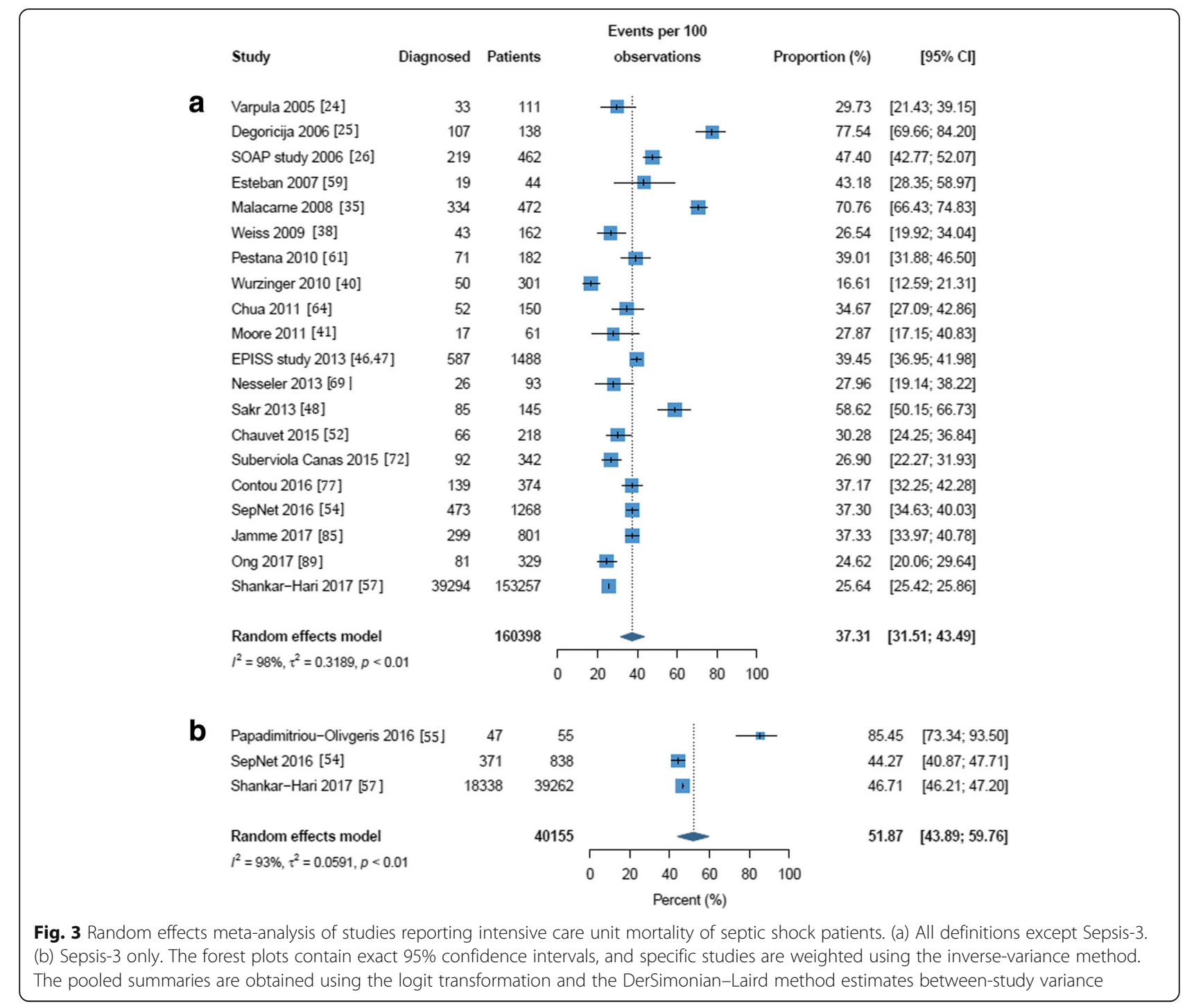

in the course of their disease and in whom a poor outcome was more likely than in those identified using Sepsis-2 criteria [104]. Our results thus support previous studies postulating that the significant shift in the diagnostic criteria from SIRS criteria to a focus on organ dysfunction would have a major impact on mortality [38, 94].

An up-to-date understanding of the incidence of septic shock and associated mortality is important to help guide resource allocation and inform healthcare budgets. Indeed, the economic costs of sepsis are a significant burden on healthcare systems. In the USA, approximately US $\$ 20$ billion is spent annually on hospital care for sepsis patients, with septic shock requiring longer ICU care and higher hospitalization costs [105]. In the UK, recent data suggest total annual hospital costs of just over $£ 1$ billion for patients with sepsis [106]. The effects of sepsis on patient health last beyond hospital discharge, with an increased mortality risk for years after hospitalization [107-109]. Nearly a quarter of sepsis survivors are readmitted to hospital within 30 days of discharge [110], and survivors often exhibit profound immune suppression, physical and psychological disorders, and impaired quality of life [107, $109,111]$. These long-term consequences greatly contribute to the high total economic cost of the disease, which is estimated to be around US\$67 billion yearly in the USA alone [105]. In the UK, the total annual costs of sepsis taking into account these indirect costs are estimated at around $£ 10$ billion [106].

The results of our review should be interpreted with consideration of certain limitations. Firstly, we only included studies published in English, potentially leading to language bias as relevant studies published 


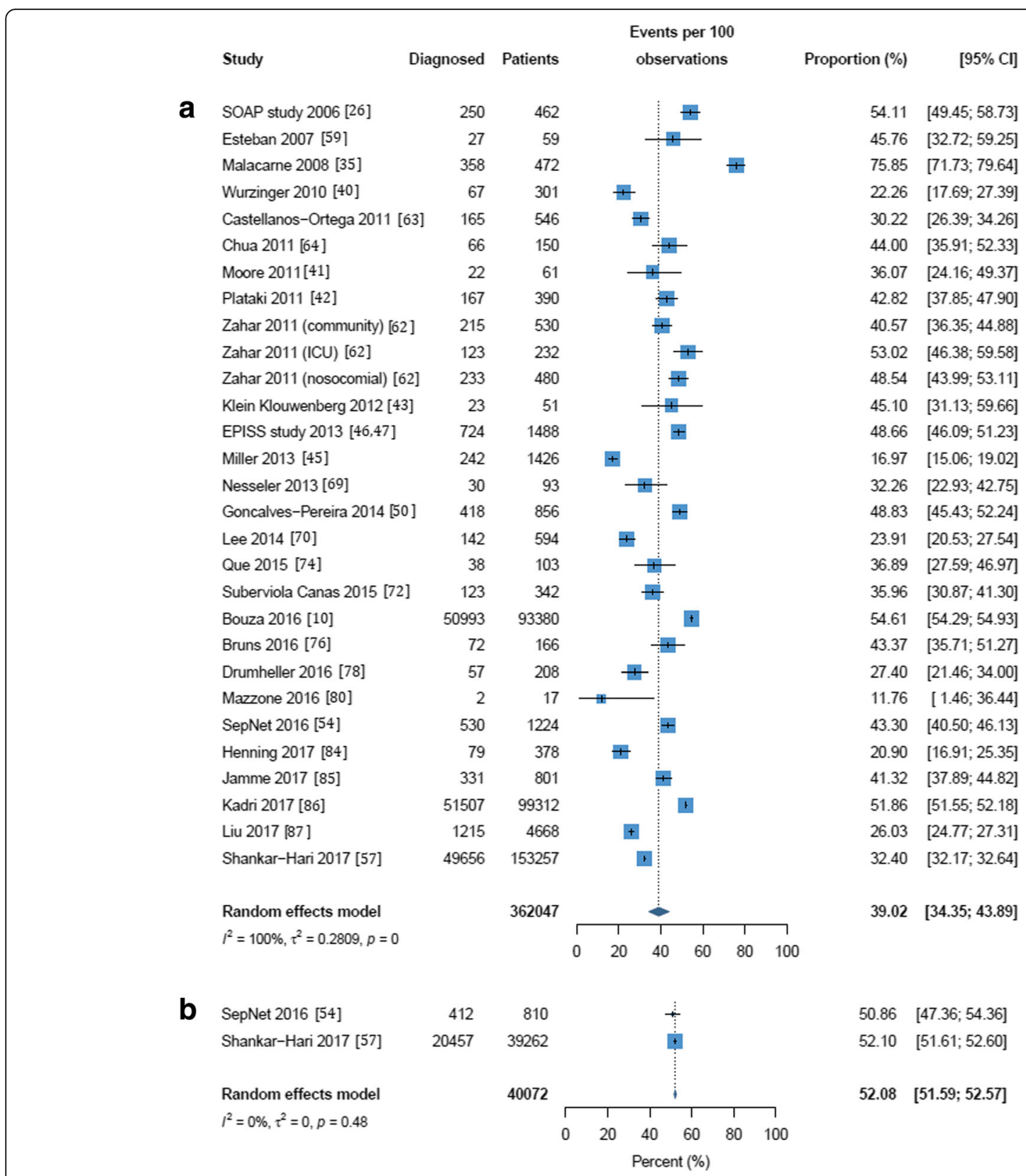

Fig. 4 Random effects meta-analysis of studies reporting hospital mortality of septic shock patients. (a) All definitions except Sepsis-3. (b) Sepsis-3 only. The forest plots contain exact 95\% confidence intervals, and specific studies are weighted using the inverse-variance method. The pooled summaries are obtained using the logit transformation and the DerSimonian-Laird method estimates between-study variance

in other languages were not included. Secondly, estimates using Sepsis-3 criteria were derived from very few studies.

\section{Conclusion}

Our findings suggest that septic shock occurs frequently in ICU patients and mortality remains high. Considerable differences in diagnostic criteria have been employed in the different studies over the last 15 years. Our review indicates that the adoption of Sepsis- 3 criteria is still at an early stage ( $\leq 3$ studies); however, as Sepsis-3 is increasingly adopted and more epidemiological studies are published in which these criteria are used, a more complete picture will emerge concerning what differences, if any, exist between countries and different care settings. This would allow a more accurate estimation of the burden of septic shock, thus enabling the development of better policies for public health planning and hospital management. 


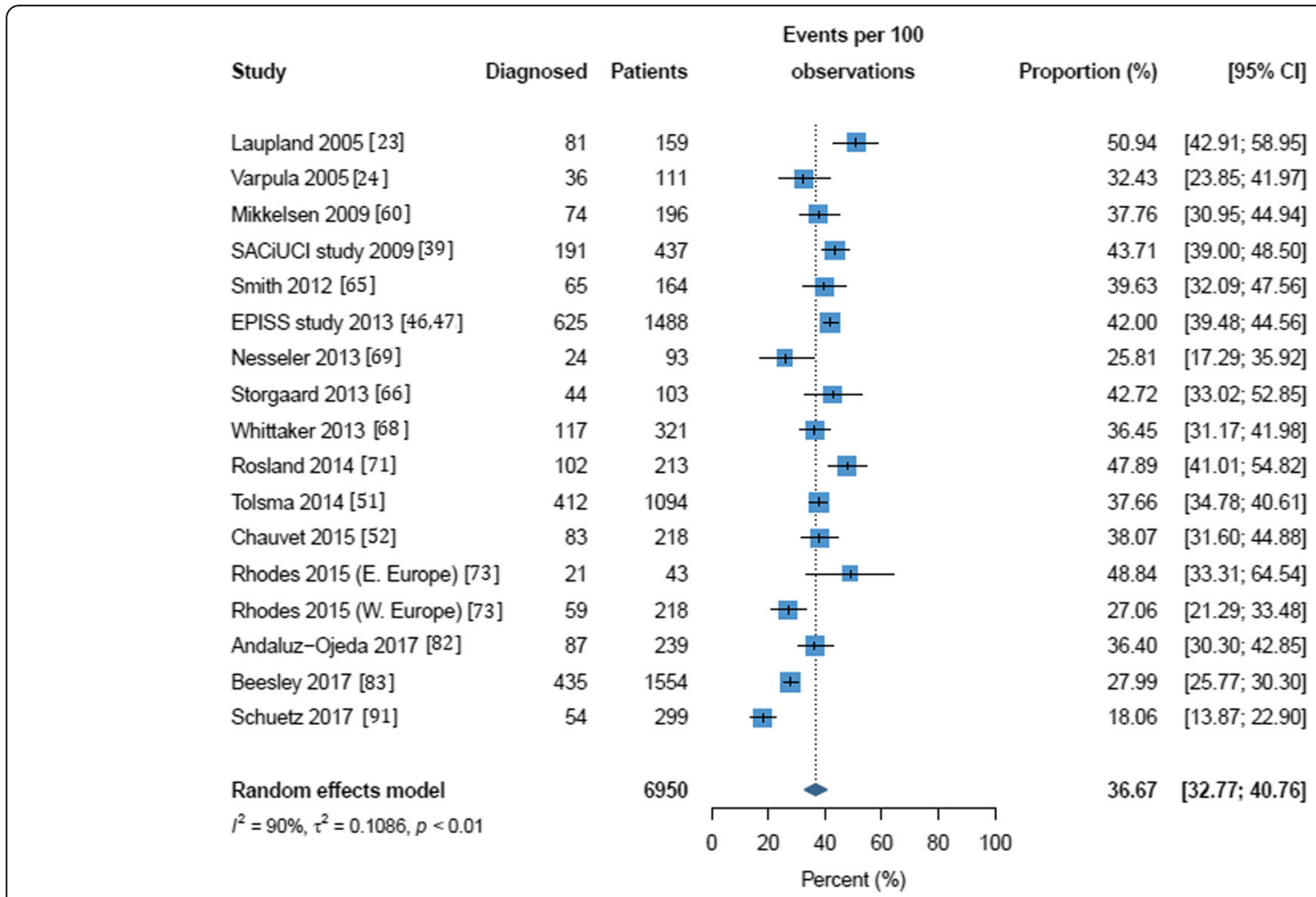

Fig. 5 Random effects meta-analysis of studies reporting 28-/30-day mortality in septic shock patients. The forest plot contains exact 95\% confidence intervals, and specific studies are weighted using the inverse-variance method. The pooled summary is obtained using the logit transformation and the DerSimonian-Laird method estimates between-study variance

\section{Additional file}

Additional file 1: Search strategy and inclusion and exclusion criteria, Tables S1-S4 and Figures S1-S11. (PDF $1970 \mathrm{~kb})$

\section{Abbreviations}

Cl: Confidence interval; EPISS: EPIdemiology of Septic Shock study; ICD: International Classification of Diseases; ICU: Intensive care unit; MeSH: Medical Subject Headings; PRISMA-P: Preferred Reporting Items for Systematic Review and Meta-Analysis Protocols; SACiUCI: Portuguese Community-Acquired Sepsis study; SIRS: Systemic inflammatory response syndrome; SOAP: Sepsis Occurrence in Acutely III Patients study

\section{Acknowledgements}

None.

\section{Funding}

This work was supported by Ferring Pharmaceuticals. However, the funding organization had no role in the collection, management, analysis, or interpretation of the data; preparation of the manuscript; or decision to submit the manuscript for publication.

\section{Availability of data and materials}

Not relevant.

\section{Authors' contributions}

EO and KKC produced the protocol. GJ, SD, EO, and KKC screened publications for inclusion in the review and carried out data extraction, validation and quality assessment of the included studies. EO and KKC wrote the manuscript with some support from GJ. SD and GJ conducted the metaanalysis and produced the forest plots. JLV provided disease area expertise and reviewed the manuscript for critical content. All authors read and approved the final manuscript.
Ethics approval and consent to participate

Not applicable.

\section{Consent for publication}

Not applicable.

\section{Competing interests}

JLV is the Editor-in-Chief of Critical Care. He has no other conflicts of interest to declare.

SD declares no competing interests.

GJ, EO, and KKC were employees of PHMR Ltd. when this work was performed. PHMR Ltd. was contracted by Ferring Pharmaceuticals to perform this systematic review and meta-analysis.

\section{Publisher's Note}

Springer Nature remains neutral with regard to jurisdictional claims in published maps and institutional affiliations.

\section{Author details}

'Department of Intensive Care, Erasme Hospital, Université libre de Bruxelles, Route de Lennik 808, 1070 Brussels, Belgium. ${ }^{2}$ PHMR Ltd., Berkeley Works, Berkley Grove, London NW1 8XY, UK.

Received: 14 March 2019 Accepted: 15 May 2019

Published online: 31 May 2019

\section{References}

1. Vincent JL, Marshall JC, Namendys-Silva SA, Francois B, Martin-Loeches I, Lipman J, et al. Assessment of the worldwide burden of critical illness: the Intensive Care Over Nations (ICON) audit. Lancet Respir Med. 2014;2:380-6.

2. Fleischmann C, Scherag A, Adhikari NK, Hartog CS, Tsaganos T, Schlattmann $P$, et al. Assessment of global incidence and mortality of hospital-treated 
sepsis. Current estimates and limitations. Am J Respir Crit Care Med. 2016; 193:259-72.

3. Liu V, Escobar GJ, Greene JD, Soule J, Whippy A, Angus DC, et al. Hospital deaths in patients with sepsis from 2 independent cohorts. JAMA. 2014;312:90-2.

4. Yeh RW, Sidney S, Chandra M, Sorel M, Selby JV, Go AS. Population trends in the incidence and outcomes of acute myocardial infarction. N Engl J Med. 2010;362:2155-65.

5. Seymour CW, Rea TD, Kahn JM, Walkey AJ, Yealy DM, Angus DC. Severe sepsis in pre-hospital emergency care: analysis of incidence, care, and outcome. Am J Respir Crit Care Med. 2012;186:1264-71.

6. Gaieski DF, Edwards JM, Kallan MJ, Carr BG. Benchmarking the incidence and mortality of severe sepsis in the United States. Crit Care Med. 2013;41:1167-74.

7. Kaukonen KM, Bailey M, Suzuki S, Pilcher D, Bellomo R. Mortality related to severe sepsis and septic shock among critically ill patients in Australia and New Zealand, 2000-2012. JAMA. 2014;311:1308-16.

8. Rhee C, Murphy MV, Li L, Platt R, Klompas M. Comparison of trends in sepsis incidence and coding using administrative claims versus objective clinical data. Clin Infect Dis. 2015;60:88-95.

9. Epstein L, Dantes R, Magill S, Fiore A. Varying estimates of sepsis mortality using death certificates and administrative codes--United States, 1999-2014. MMWR Morb Mortal Wkly Rep. 2016;65:342-5.

10. Bouza C, Lopez-Cuadrado T, Amate-Blanco JM. Use of explicit ICD9-CM codes to identify adult severe sepsis: impacts on epidemiological estimates. Crit Care. 2016;20:313.

11. Gohil SK, Cao C, Phelan M, Tjoa T, Rhee C, Platt R, et al. Impact of policies on the rise in sepsis incidence, 2000-2010. Clin Infect Dis. 2016;62:695-703.

12. Vincent JL, Lefrant JY, Kotfis K, Nanchal R, Martin-Loeches I, Wittebole X, et al. Comparison of European ICU patients in 2012 (ICON) versus 2002 (SOAP). Intensive Care Med. 2018:44:337-44.

13. Vincent JL, De Backer D. Circulatory shock. N Engl J Med. 2013;369:1726-34.

14. Singer M, Deutschman CS, Seymour CW, Shankar-Hari M, Annane D, Bauer $M$, et al. The third international consensus definitions for sepsis and septic shock (Sepsis-3). JAMA. 2016;315:801-10.

15. Shankar-Hari M, Phillips GS, Levy ML, Seymour CW, Liu VX, Deutschman CS, et al. Developing a new definition and assessing new clinical criteria for septic shock: for the third international consensus definitions for sepsis and septic shock (Sepsis-3). JAMA. 2016;315:775-87.

16. Moher D, Shamseer $L$, Clarke M, Ghersi D, Liberati A, Petticrew $M$, et al. Preferred reporting items for systematic review and meta-analysis protocols (PRISMA-P) 2015 statement. Syst Rev. 2015;4:1.

17. Higgins JPT, Green S. Cochrane handbook for systematic reviews of interventions. Hoboken: Wiley; 2011.

18. Centre for Reviews and Dissemination. Systematic reviews: CRD's guidance for undertaking reviews in health care. York: Centre for Reviews and Dissemination; 2009

19. The Joanna Briggs Institute. Joanna Briggs Institute Reviewers' Manual. Adelaide: The Joanna Briggs Institute; 2014.

20. Moola S, Munn Z, Tufanaru C, Aromataris E, Sears K, Sfetcu R, et al. Systematic reviews of etiology and risk. In: Joanna Briggs Institute Reviewer's Manual. Adelaide: The Joanna Briggs Institute; 2017.

21. Higgins JP, Thompson SG, Deeks JJ, Altman DG. Measuring inconsistency in meta-analyses. BMJ. 2003;327:557-60.

22. Adrie C, Alberti C, Chaix-Couturier C, Azoulay E, De LA, Cohen Y, et al. Epidemiology and economic evaluation of severe sepsis in France: age, severity, infection site, and place of acquisition (community, hospital, or intensive care unit) as determinants of workload and cost. J Crit Care. 2005;20:46-58.

23. Laupland KB, Zygun DA, Doig CJ, Bagshaw SM, Svenson LW, Fick GH. Oneyear mortality of bloodstream infection-associated sepsis and septic shock among patients presenting to a regional critical care system. Intensive Care Med. 2005:31:213-9.

24. Varpula M, Tallgren M, Saukkonen K, Voipio-Pulkki LM, Pettila V. Hemodynamic variables related to outcome in septic shock. Intensive Care Med. 2005;31:1066-71.

25. Degoricija V, Sharma M, Legac A, Gradiser M, Sefer S, Vucicevic Z. Survival analysis of 314 episodes of sepsis in medical intensive care unit in university hospital: impact of intensive care unit performance and antimicrobial therapy. Croat Med J. 2006;47:385-97.

26. Vincent JL, Sakr Y, Sprung CL, Ranieri VM, Reinhart K, Gerlach H, et al. Sepsis in European intensive care units: results of the SOAP study. Crit Care Med. 2006;34:344-53.
27. Sakr Y, Reinhart K, Vincent JL, Sprung CL, Moreno R, Ranieri VM, et al. Does dopamine administration in shock influence outcome? Results of the Sepsis Occurrence in Acutely III Patients (SOAP) Study. Crit Care Med. 2006;34:589-97.

28. Sprung $C L$, Sakr $Y$, Vincent JL, Le Gall JR, Reinhart K, Ranieri VM, et al. An evaluation of systemic inflammatory response syndrome signs in the Sepsis Occurrence In Acutely III Patients (SOAP) study. Intensive Care Med. 2006;32:421-7.

29. Engel C, Brunkhorst FM, Bone HG, Brunkhorst R, Gerlach H, Grond S, et al. Epidemiology of sepsis in Germany: results from a national prospective multicenter study. Intensive Care Med. 2007;33:606-18.

30. Guidet B, Mosqueda GJ, Priol G, Aegerter P. The COASST study: costeffectiveness of albumin in severe sepsis and septic shock. J Crit Care. 2007;22:197-203.

31. Karlsson S, Varpula M, Ruokonen E, Pettila V, Parviainen I, Ala-Kokko TI, et al. Incidence, treatment, and outcome of severe sepsis in ICU-treated adults in Finland: the Finnsepsis study. Intensive Care Med. 2007;33:435-43.

32. Sakr $Y$, Vincent $J$, Schuerholz T, Filipescu D, Romain A, Hjelmqvist $H$, et al. Early- versus late-onset shock in European intensive care units. Shock. 2007;28:636-43.

33. Blanco J, Muriel-Bombin A, Sagredo V, Taboada F, Gandia F, Tamayo L, et al. Incidence, organ dysfunction and mortality in severe sepsis: a Spanish multicentre study. Crit Care. 2008;12:R158.

34. Elke G, Schadler D, Engel C, Bogatsch H, Frerichs I, Ragaller M, et al. Current practice in nutritional support and its association with mortality in septic patients--results from a national, prospective, multicenter study. Crit Care Med. 2008;36:1762-7.

35. Malacarne $P$, Langer M, Nascimben E, Moro ML, Giudici D, Lampati L, et al. Building a continuous multicenter infection surveillance system in the intensive care unit: findings from the initial data set of 9,493 patients from 71 Italian intensive care units. Crit Care Med. 2008;36:1105-13.

36. Adrie C, Francais A, Alvarez-Gonzalez A, Mounier R, Azoulay E, Zahar JR, et al. Model for predicting short-term mortality of severe sepsis. Crit Care. 2009;13:R72

37. Povoa PR, Carneiro AH, Ribeiro OS, Pereira AC. Influence of vasopressor agent in septic shock mortality. Results from the Portuguese CommunityAcquired Sepsis Study (SACiUCI study). Crit Care Med. 2009;37:410-6.

38. Weiss M, Huber-Lang M, Taenzer M, Traeger K, Altherr J, Kron M, et al. Different patient case mix by applying the 2003 SCCM/ESICM/ACCP/ATS/SIS sepsis definitions instead of the 1992 ACCP/SCCM sepsis definitions in surgical patients: a retrospective observational study. BMC Med Inform Decis Mak. 2009;9:25.

39. Cardoso T, Carneiro AH, Ribeiro O, Teixeira-Pinto A, Costa-Pereira A. Reducing mortality in severe sepsis with the implementation of a core 6hour bundle: results from the Portuguese community-acquired sepsis study (SACiUCl study). Crit Care. 2010;14:R83.

40. Wurzinger B, Dunser MW, Wohlmuth $C$, Deutinger MC, Ulmer $H$, Torgersen $\mathrm{C}$, et al. The association between body-mass index and patient outcome in septic shock: a retrospective cohort study. Wien Klin Wochenschr. 2010;122:31-6.

41. Moore $\sqcup$, McKinley BA, Turner KL, Todd SR, Sucher JF, Valdivia A, et al. The epidemiology of sepsis in general surgery patients. J Trauma. 2011;70:672-80

42. Plataki M, Kashani K, Cabello-Garza J, Maldonado F, Kashyap R, Kor DJ, et al. Predictors of acute kidney injury in septic shock patients: an observational cohort study. Clin J Am Soc Nephrol. 2011;6:1744-51.

43. Klein Klouwenberg PM, Ong DS, Bonten MJ, Cremer OL. Classification of sepsis, severe sepsis and septic shock: the impact of minor variations in data capture and definition of SIRS criteria. Intensive Care Med. 2012;38:811-9.

44. Almeida M, Ribeiro O, Aragao I, Costa-Pereira A, Cardoso T. Differences in compliance with Surviving Sepsis Campaign recommendations according to hospital entrance time: day versus night. Crit Care. 2013;17:R79.

45. Miller RR III, Dong L, Nelson NC, Brown SM, Kuttler KG, Probst DR, et al. Multicenter implementation of a severe sepsis and septic shock treatment bundle. Am J Respir Crit Care Med. 2013;188:77-82.

46. Pavon A, Binquet C, Kara F, Martinet O, Ganster F, Navellou JC, et al. Profile of the risk of death after septic shock in the present era: an epidemiologic study. Crit Care Med. 2013:41:2600-9.

47. Quenot JP, Binquet C, Kara F, Martinet O, Ganster F, Navellou JC, et al. The epidemiology of septic shock in French intensive care units: the prospective multicenter cohort EPISS study. Crit Care. 2013;17:R65.

48. Sakr Y, Elia C, Mascia L, Barberis B, Cardellino S, Livigni S, et al. Epidemiology and outcome of sepsis syndromes in Italian ICUs: a muticentre, 
observational cohort study in the region of Piedmont. Minerva Anestesiol. 2013;79:993-1002.

49. Sakr Y, Elia C, Mascia L, Barberis B, Cardellino S, Livigni S, et al. The influence of gender on the epidemiology of and outcome from severe sepsis. Crit Care. 2013;17:R50

50. Goncalves-Pereira J, Pereira JM, Ribeiro O, Baptista JP, Froes F, Paiva JA. Impact of infection on admission and of the process of care on mortality of patients admitted to the intensive care unit: the INFAUCI study. Clin Microbiol Infect. 2014;20:1308-15.

51. Tolsma V, Schwebel C, Azoulay E, Darmon M, Souweine B, Vesin A, et al. Sepsis severe or septic shock: outcome according to immune status and immunodeficiency profile. Chest. 2014;146:1205-13.

52. Chauvet JL, El-Dash S, Delastre O, Bouffandeau B, Jusserand D, Michot JB, et al. Early dynamic left intraventricular obstruction is associated with hypovolemia and high mortality in septic shock patients. Crit Care. 2015;19:262

53. Kubler A, Adamik B, Ciszewicz-Adamiczka B, Ostrowska E. Severe sepsis in intensive care units in Poland--a point prevalence study in 2012 and 2013. Anaesthesiol Intensive Ther. 2015;47:315-9.

54. SepNet Critical Care Trials Group. Incidence of severe sepsis and septic shock in German intensive care units: the prospective, multicentre INSEP study. Intensive Care Med. 2016;42:1980-9.

55. Papadimitriou-Olivgeris M, Aretha D, Zotou A, Koutsileou K, Zbouki A, Lefkaditi $A$, et al. The role of obesity in sepsis outcome among critically ill patients: a retrospective cohort analysis. Biomed Res Int. 2016;2016:5941279.

56. van Vught $L A$, Klein Klouwenberg PM, Spitoni C, Scicluna BP, Wiewel MA, Horn J, et al. Incidence, risk factors, and attributable mortality of secondary infections in the intensive care unit after admission for sepsis. JAMA. 2016;315:1469-79.

57. Shankar-Hari M, Harrison DA, Rubenfeld GD, Rowan K. Epidemiology of sepsis and septic shock in critical care units: comparison between sepsis-2 and sepsis-3 populations using a national critical care database. $\mathrm{Br} J$ Anaesth. 2017;119:626-36.

58. Kumar A, Roberts D, Wood KE, Light B, Parrillo JE, Sharma S, et al. Duration of hypotension before initiation of effective antimicrobial therapy is the critical determinant of survival in human septic shock. Crit Care Med. 2006;34:1589-96.

59. Esteban A, Frutos-Vivar F, Ferguson ND, Penuelas O, Lorente JA, Gordo F, et al. Sepsis incidence and outcome: contrasting the intensive care unit with the hospital ward. Crit Care Med. 2007:35:1284-9.

60. Mikkelsen ME, Miltiades AN, Gaieski DF, Goyal M, Fuchs BD, Shah CV, et al. Serum lactate is associated with mortality in severe sepsis independent of organ failure and shock. Crit Care Med. 2009;37:1670-7.

61. Pestana D, Espinosa E, Sanguesa-Molina JR, Ramos R, Perez-Fernandez E, Duque $M$, et al. Compliance with a sepsis bundle and its effect on intensive care unit mortality in surgical septic shock patients. J Trauma. 2010;69:1282-7.

62. Zahar JR, Timsit JF, Garrouste-Orgeas M, Francais A, Vesin A, DescorpsDeclere A, et al. Outcomes in severe sepsis and patients with septic shock: pathogen species and infection sites are not associated with mortality. Crit Care Med. 2011;39:1886-95.

63. Castellanos-Ortega A, Suberviola B, Garcia-Astudillo LA, Ortiz F, Llorca J, Delgado-Rodriguez M. Late compliance with the sepsis resuscitation bundle: impact on mortality. Shock. 2011;36:542-7.

64. Chua D, Choice K, Gellatly R, Brown G. Statin use and morbidity outcomes in septic shock patients: a retrospective study. Crit Care Shock. 2011;14:15-8.

65. Smith SH, Perner A. Higher vs. lower fluid volume for septic shock: clinical characteristics and outcome in unselected patients in a prospective, multicenter cohort. Crit Care. 2012;16:R76.

66. Storgaard M, Hallas J, Gahrn-Hansen B, Pedersen SS, Pedersen C, Lassen AT. Short- and long-term mortality in patients with community-acquired severe sepsis and septic shock. Scand J Infect Dis. 2013;45:577-83.

67. Walkey AJ, Wiener RS, Lindenauer PK. Utilization patterns and outcomes associated with central venous catheter in septic shock: a population-based study. Crit Care Med. 2013;41:1450-7.

68. Whittaker SA, Mikkelsen ME, Gaieski DF, Koshy S, Kean C, Fuchs BD. Severe sepsis cohorts derived from claims-based strategies appear to be biased toward a more severely ill patient population. Crit Care Med. 2013;41:945-53.

69. Nesseler N, Defontaine A, Launey Y, Morcet J, Malledant Y, Seguin P. Longterm mortality and quality of life after septic shock: a follow-up observational study. Intensive Care Med. 2013;39:881-8.

70. Lee SJ, Ramar K, Park JG, Gajic O, Li G, Kashyap R. Increased fluid administration in the first three hours of sepsis resuscitation is associated with reduced mortality: a retrospective cohort study. Chest. 2014;146:908-15.
71. Rosland RG, Hagen MU, Haase N, Holst LB, Plambech M, Madsen KR, et al. Red blood cell transfusion in septic shock - clinical characteristics and outcome of unselected patients in a prospective, multicentre cohort. Scand J Trauma Resusc Emerg Med. 2014;22:14.

72. Suberviola Canas B, Jauregui R, Ballesteros MA, Leizaola O, Gonzalez-Castro A, Castellanos-Ortega A. Effects of antibiotic administration delay and inadequacy upon the survival of septic shock patients. Med Int. 2015;39:459-66.

73. Rhodes A, Phillips G, Beale R, Cecconi M, Chiche JD, De Backer D, et al. The Surviving Sepsis Campaign bundles and outcome: results from the International Multicentre Prevalence Study on Sepsis (the IMPreSS study). Intensive Care Med. 2015;41:1620-8.

74. Que YA, Guessous I, Dupuis-Lozeron E, de Oliveira CRA, Oliveira CF, Graf R, et al. Prognostication of mortality in critically ill patients with severe infections. Chest. 2015;148:674-82.

75. Ala-Kokko TI, Mutt SJ, Nisula S, Koskenkari J, Liisanantti J, Ohtonen P, et al. Vitamin $\mathrm{D}$ deficiency at admission is not associated with 90-day mortality in patients with severe sepsis or septic shock: observational FINNAKI cohort study. Ann Med. 2016;48:67-75.

76. Bruns BR, Lissauer M, Tesoriero R, Narayan M, Buchanan L, Galvagno SM Jr, et al. Infectious complications and mortality in an American acute care surgical service. Eur J Trauma Emerg Surg. 2016:42:243-7.

77. Contou D, Roux D, Jochmans S, Coudroy R, Guerot E, Grimaldi D, et al. Septic shock with no diagnosis at 24 hours: a pragmatic multicenter prospective cohort study. Crit Care. 2016;20:360.

78. Drumheller BC, Agarwal A, Mikkelsen ME, Sante SC, Weber AL, Goyal M, et al. Risk factors for mortality despite early protocolized resuscitation for severe sepsis and septic shock in the emergency department. J Crit Care. 2016;31:13-20.

79. Jones SL, Ashton CM, Kiehne LB, Nicolas JC, Rose AL, Shirkey BA, et al. Outcomes and resource use of sepsis-associated stays by presence on admission, severity, and hospital type. Med Care. 2016;54:303-10.

80. Mazzone A, Dentali F, La RM, Foglia E, Gambacorta M, Garagiola E, et al. Clinical features, short-term mortality, and prognostic risk factors of septic patients admitted to internal medicine units: results of an Italian multicenter prospective study. Medicine (Baltimore). 2016;95:e2124.

81. Adams C, Tucker C, Allen B, McRae A, Balazh J, Horst S, et al. Disparities in hemodynamic resuscitation of the obese critically ill septic shock patient. J Crit Care. 2017:37:219-23.

82. Andaluz-Ojeda D, Nguyen HB, Meunier-Beillard N, Cicuendez R, Quenot JP, Calvo D, et al. Superior accuracy of mid-regional proadrenomedullin for mortality prediction in sepsis with varying levels of illness severity. Ann Intensive Care. 2017;7:15.

83. Beesley SJ, Wilson EL, Lanspa MJ, Grissom CK, Shahul S, Talmor D, et al. Relative bradycardia in patients with septic shock requiring vasopressor therapy. Crit Care Med. 2017;45:225-33.

84. Henning DJ, Carey JR, Oedorf K, Day DE, Redfield CS, Huguenel CJ, et al. The absence of fever is associated with higher mortality and decreased antibiotic and IV fluid administration in emergency department patients wiith suspected septic shock. Crit Care Med. 2017:45:e575-82.

85. Jamme M, Daviaud F, Charpentier J, Marin N, Thy M, Hourmant Y, et al. Time course of septic shock in immunocompromised and nonimmunocompromised patients. Crit Care Med. 2017;45:2031-9.

86. Kadri SS, Rhee C, Strich JR, Morales MK, Hohmann S, Menchaca J, et al. Estimating ten-year trends in septic shock incidence and mortality in United States academic medical centers using clinical data. Chest. 2017;151:278-85.

87. Liu VX, Fielding-Singh V, Greene JD, Baker JM, Iwashyna TJ, Bhattacharya J, et al. The timing of early antibiotics and hospital mortality in sepsis. Am J Respir Crit Care Med. 2017;196:856-63.

88. Marik PE, Linde-Zwirble WT, Bittner EA, Sahatjian J, Hansell D. Fluid administration in severe sepsis and septic shock, patterns and outcomes: an analysis of a large national database. Intensive Care Med. 2017;43:625-32.

89. Ong DSY, Bonten MJM, Spitoni C, Verduyn Lunel FM, Frencken JF, Horn J, et al. Epidemiology of multiple herpes viremia in previously immunocompetent patients with septic shock. Clin Infect Dis. 2017;64:1204-10.

90. Saqib A, Ibrahim U, Patel P, Joshi A, Chalhoub M. Mortality among high-risk patients admitted with septic shock to U.S. teaching hospitals in July: does the 'July Effect' exist? Heart Lung. 2017;46:110-3.

91. Schuetz P, Birkhahn R, Sherwin R, Jones AE, Singer A, Kline JA, et al. Serial procalcitonin predicts mortality in severe sepsis patients: results from the Multicenter Procalcitonin MOnitoring SEpsis (MOSES) Study. Crit Care Med. 2017:45:781-9. 
92. Henning DJ, Puskarich MA, Self WH, Howell MD, Donnino MW, Yealy DM, et al. An emergency department validation of the SEP-3 sepsis and septic shock definitions and comparison with 1992 consensus definitions. Ann Emerg Med. 2017;70:544-52.

93. Sartelli M, Kluger Y, Ansaloni L, Hardcastle TC, Rello J, Watkins RR, et al. Raising concerns about the Sepsis-3 definitions. World J Emerg Surg. 2018;13:6.

94. Weiss M, Huber-Lang M, Taenzer M, Kron M, Hay B, Nass M, et al. How many general and inflammatory variables need to be fulfilled when defining sepsis due to the 2003 SCCM/ESICM/ACCP/ATS/SIS definitions in critically ill surgical patients: a retrospective observational study. BMC Anesthesiol. 2010;10:22.

95. Fleischmann-Struzek C, Thomas-Ruddel DO, Schettler A, Schwarzkopf D, Stacke A, Seymour CW, et al. Comparing the validity of different ICD coding abstraction strategies for sepsis case identification in German claims data. PLoS One. 2018;13:e0198847.

96. Sjoding MW, Hyzy RC. Septic shock surveillance: critically important but not straightforward. Chest. 2017;151:247-8.

97. Brun-Buisson C, Doyon F, Carlet J, Dellamonica P, Gouin F, Lepoutre A, et al. Incidence, risk factors, and outcome of severe sepsis and septic shock in adults. A multicenter prospective study in intensive care units. French ICU Group for Severe Sepsis. JAMA. 1995;274:968-74.

98. Annane D, Aegerter P, Jars-Guincestre MC, Guidet B. Current epidemiology of septic shock: the CUB-Rea Network. Am J Respir Crit Care Med. 2003;168:165-72.

99. Dombrovskiy VY, Martin AA, Sunderram J, Paz HL. Rapid increase in hospitalization and mortality rates for severe sepsis in the United States: a trend analysis from 1993 to 2003. Crit Care Med. 2007;35:1244-50.

100. Levy MM, Dellinger RP, Townsend SR, Linde-Zwirble WT, Marshall JC, Bion J, et al. The Surviving Sepsis Campaign: results of an international guidelinebased performance improvement program targeting severe sepsis. Crit Care Med. 2010;38:367-74.

101. Pene F, Percheron S, Lemiale V, Viallon V, Claessens YE, Marque S, et al. Temporal changes in management and outcome of septic shock in patients with malignancies in the intensive care unit. Crit Care Med. 2008;36:690-6.

102. Zuber B, Tran TC, Aegerter P, Grimaldi D, Charpentier J, Guidet B, et al. Impact of case volume on survival of septic shock in patients with malignancies. Crit Care Med. 2012;40:55-62.

103. Shankar-Hari M, Ambler M, Mahalingasivam V, Jones A, Rowan K, Rubenfeld GD. Evidence for a causal link between sepsis and long-term mortality: a systematic review of epidemiologic studies. Crit Care. 2016:20:101.

104. Kashyap R, Singh TD, Rayes H, O'Horo JC, Wilson G, Bauer P, et al. Association of septic shock definitions and standardized mortality ratio in a contemporary cohort of critically ill patients. J Crit Care. 2019;50:269-74.

105. Tiru B, DiNino EK, Orenstein A, Mailloux PT, Pesaturo A, Gupta A, et al. The economic and humanistic burden of severe sepsis. Pharmacoeconomics. 2015;33:925-37.

106. York Health Economics Consortium. The Cost of Sepsis Care in the UK. Available at: http://allcatsrgrey.org.uk/wp/download/health_economics/ YHEC-Sepsis-Report-17.02.17-FINAL.pdf. Accessed 29 Apr 19.

107. Yende S, Austin S, Rhodes A, Finfer S, Opal S, Thompson T, et al. Long-term quality of life among survivors of severe sepsis: analyses of two international trials. Crit Care Med. 2016;44:1461-7.

108. Wang HE, Szychowski JM, Griffin R, Safford MM, Shapiro NI, Howard G. Long-term mortality after community-acquired sepsis: a longitudinal population-based cohort study. BMJ Open. 2014;4:e004283.

109. Winters BD, Eberlein M, Leung J, Needham DM, Pronovost PJ, Sevransky JE. Long-term mortality and quality of life in sepsis: a systematic review. Crit Care Med. 2010;38:1276-83.

110. Goodwin AJ, Rice DA, Simpson KN, Ford DW. Frequency, cost, and risk factors of readmissions among severe sepsis survivors. Crit Care Med. 2015;43:738-46.

111. Quartin AA, Schein RM, Kett DH, Peduzzi PN. Magnitude and duration of the effect of sepsis on survival. Department of Veterans Affairs Systemic Sepsis Cooperative Studies Group. JAMA. 1997;277:1058-63.

\section{Ready to submit your research? Choose BMC and benefit from:}

- fast, convenient online submission

- thorough peer review by experienced researchers in your field

- rapid publication on acceptance

- support for research data, including large and complex data types

- gold Open Access which fosters wider collaboration and increased citations

- maximum visibility for your research: over $100 \mathrm{M}$ website views per year

At BMC, research is always in progress.

Learn more biomedcentral.com/submissions 